\title{
Fever in Young Lambs: Carotid Denervation Alters the Febrile Response to a Small Dose of Bacterial Pyrogen
}

\author{
JAMES E. FEWELL \\ with the technical assistance of Colleen S. Kondo \\ Reproductive Medicine Research Group, Department of Obstetrics and Gynaecology, Medical Physiology, and \\ Paediatrics, University of Calgary, Health Sciences Centre, Calgary, Alberta T2N 4NI, Canada
}

\begin{abstract}
Experiments were done on 13 young lambs to determine if carotid denervation influences the cardiovascular and metabolic responses to i.v. administration of bacterial pyrogen [Salmonella abortus equi (SAE) $0.3 \mu \mathrm{g}$ ]. Each lamb was anesthetized with halothane and prepared for measurements of cardiac output, arterial and mixed venous oxygen saturations, and body core temperature. No sooner than $3 \mathrm{~d}$ after surgery, measurements were made during a control period and at 10-min intervals for $120 \mathrm{~min}$ after i.v. administration of SAE in seven carotid-intact lambs and six carotid-denervated lambs. Administration of SAE produced a short-lived fever of about $1^{\circ} \mathrm{C}$ in the carotid-intact lambs, whereas no change in body core temperature was observed in the carotid-denervated lambs. In carotid-intact lambs, the rise in body core temperature began approximately $40 \mathrm{~min}$ after administration of SAE and continued for approximately $50 \mathrm{~min}$. This rise in body core temperature was preceded by the onset of shivering and an increase in total body oxygen consumption. Carotid denervation produced changes in some of the cardiovascular variables during the control period (i.e. arterial oxygen content, cardiac index, heart rate, and pulmonary blood pressure); however, there were no additional significant changes in any of the metabolic or cardiovascular variables after administration of SAE. The mechanism of these unexpected findings remains to be determined. (Pediatr Res 31: 107-111, 1992)
\end{abstract}

\section{Abbreviations}

SAE, salmonella abortus equi

NTS, nucleus tractus solitarus

Newborn animals of a number of species, such as the guinea pig (1), rabbit (2), and sheep (3), have an attenuated or absent febrile response to bacterial pyrogen. This occurs even though these animals exhibit a thermogenic response to a decrease in ambient temperature $(4,5)$. Although the reason for this attenuated or absent febrile response to bacterial pyrogen is not entirely clear, recent experiments provide evidence that arginine

Received May 7, 1991; accepted September 5, 1991.

Correspondence and reprint requests: James E. Fewell, Ph.D., Heritage Medical Research Building, University of Calgary, 3330 Hospital Drive, N.W., Calgary, Alberta T2N 4N1, Canada.

Supported by The Heart and Stroke Foundation of Canada and The Nat Christie Unit for the Study of Human Reproduction. This work was done during Dr. Fewell's tenure as an Established Investigator of the American Heart Association and a Heritage Medical Scholar of the Alberta Heritage Foundation for Medical Research. vasopressin, which may function as a physiologically important antipyretic substance in the brain (6), plays a role (7).

We have recently shown that carotid-intact lambs develop a fever of approximately $0.7^{\circ} \mathrm{C}$ in response to a small dose of bacterial pyrogen (i.e. $0.3 \mu \mathrm{g}$ SAE lipopolysaccharide) by the $3 \mathrm{rd}$ wk of postnatal life (8). Previous experiments on adult rats have provided evidence that discrete bilateral lesions of the NTS, which disrupts afferent neural activity from the arterial baroreceptors, alter the cardiovascular and metabolic responses to thermogenic stimuli (i.e. a change in ambient temperature) (9). With this in mind, the present experiments have been done to determine whether carotid denervation alters the temperature and the cardiorespiratory or metabolic responses to bacterial pyrogen in young lambs.

\section{MATERIALS AND METHODS}

Thirteen lambs ranging in age from 14 to $28 \mathrm{~d}$ were studied. Each lamb was separated from its ewe 3 to $7 \mathrm{~d}$ after birth and was housed in our laboratory in a Plexiglas cage with continuous access to milk (Lamb Milk Replacer; Land O'Lakes, Inc., Fort Dodge, IA). The lambs were among other lambs, fed and slept ad libitum, and soon became accustomed to their surroundings and the laboratory personnel.

Surgical preparation. Each lamb underwent one operation before study. For surgery, each lamb was given atropine sulfate $(0.2 \mathrm{mg} / \mathrm{kg}$ s.c. $)$ and anesthesia was induced by having the lamb breathe 3 to $4 \%$ halothane in oxygen via a mask. The trachea was then intubated with a cuffed endotracheal tube, and anesthesia was maintained by ventilating the lamb's lungs with 0.5 to $1.0 \%$ halothane in oxygen. An electrocardiogram, end-tidal carbon dioxide levels, and rectal temperature were monitored during surgery; body temperature was kept near $39^{\circ} \mathrm{C}$ with a heating pad and end-tidal carbon dioxide levels were kept near $5 \%$ with a volume-cycled ventilator.

The operation was done on lambs aged between 11 and $25 \mathrm{~d}$. A midline sternotomy was performed to expose the heart and great vessels. The pericardium was incised and a precalibrated electromagnetic flow transducer (SP 7515, inner diameter 9.0 or $10.0 \mathrm{~mm}$; Gould-Statham, Inc., Oxnard, CA) was placed around the main pulmonary artery to measure pulmonary blood flow. Two double-lumen fiberoptic catheter oximeters (model U440 Opticath; Oximetrix, Inc., Mountain View, CA) treated with TDMAC heparin complex (Polysciences Inc., Warrington, PA) were placed to measure blood pressures and $\mathrm{Hb}$ oxygen saturations: one in the aorta and one in the pulmonary artery. In addition, a copper/constantan thermocouple (RET-1; Sensortek, Clifton, NJ) was inserted to the inferior vena cava via a femoral vein to measure body core temperature.

Electrodes for the following recordings were also implanted: electrocorticogram (recorded from electrodes placed through 
burr holes to lie over the parietal cortex), electro-oculogram (recorded from electrodes placed at the inner and outer canthus of the right eye), nuchal electromyogram (recorded from electrodes placed in the dorsal cervical musculature), and diaphragm electromyogram (recorded from electrodes placed transabdominally into muscle fibers adjacent to the lateral margin of the central tendon of the right hemidiaphragm). A reference wire was sutured into the s.c. tissue of the scalp. The electrodes were made in our laboratory and were paired, Teflon-coated, multistranded, stainless steel wires (AS 633; Cooner Wire Co., Chatsworth, CA); approximately $3 \mathrm{~mm}$ of the tip of each was bared for implantation. The proximal end of each wire was bared and soldered to the appropriate pin of an 18-pin electrical plug, which was interfaced with four differential high impedance probes (7HIP5G; Grass Medical Instruments, Quincy, MA) during a study.

Carotid denervation was performed in six of the 13 lambs as follows. The carotid body and carotid sinus were approached as described by Appleton and Waites (10) and denervated as described by Bureau et al. (11). Briefly, the denervation procedure consisted of: 1) cutting the sinus nerve, 2) stripping the adventitia from the wall of the carotid artery from the origin of the lingual artery to $0.5 \mathrm{~cm}$ below the origin of the occipital artery, 3) removing all fibroadipose nodular tissue from around the occipital-carotid artery junction, 4) sectioning all minute vessels arising in the area of the carotid and occipital artery bifurcation, 5) stripping the adventitia from the wall of the occipital artery for $1 \mathrm{~cm}$ from its origin from the carotid artery, and, lastly, 6) painting the walls of the stripped vessels with $7 \%$ phenol.

The lambs were allowed to recover from surgery in a ShorLine intensive care unit for small animals (Schroer Manufacturing Company, Kansas City, MO) and were then returned to their Plexiglas study cage in our sleep laboratory but were not studied before the $3 \mathrm{rd}$ postoperative day. Each lamb received antibiotics daily (penicillin $\mathrm{G}$ and dihydrostreptomycin), beginning on the day of surgery.

Conditions of observations. Our sleep laboratory consists of a large room that contains two sound-attenuating chambers. Temperature, sound, and lighting can be precisely controlled in each chamber. The lambs in this series of experiments were raised in an environmental temperature of $25 \pm 1^{\circ} \mathrm{C}$. Each chamber also has a one-way viewing mirror as well as a closed-circuit video system to observe the lambs. Our recording equipment was kept in the room adjacent to the chamber. Before a study, a partition was placed in the cage to prevent the animal from turning around once the catheters, electrodes, and cables were connected. However, the lamb could still lay down, stand up, and feed ad libitum.

For an experiment, the optical sensors were connected to the optical modules of the oximeter processors and the vascular catheters were connected to strain gauge manometers (Gould P23ID; Gould, Inc., Oxnard, CA) using rigid pressure-monitoring tubes; the strain gauge manometers were placed at the approximate level of the heart when the animal was lying down. The flow transducer cable was connected to a Gould SP2202 Blood Flowmeter (Gould, Inc.) and the thermocouple was connected to an Iso-Thermix Unit (Columbus Instruments International Corp., Columbus, OH) that was interfaced with a Zenith Lap-Top Computer (model ZA-180-21). The 18-pin electrical plug was connected to the differential high-impedance probes; a heavy duty cable connected the differential high-impedance probes to A.C. preamplifiers (model 7P5 Wide Band A.C. EEG Pre-amplifier; Grass Medical Instruments) in the adjacent room. The electrophysiologic signals were filtered as follows: electrocorticogram $1-35 \mathrm{~Hz}$, electro-oculogram $0.3-35 \mathrm{~Hz}$, and electromyograms 3-35 Hz.

The following electrophysiologic criteria were used to define sleep state. During wakefulness, the electrocorticogram showed a fast wave-low voltage pattern; there were occasional eye movements and there was tonic activity on the nuchal electromyogram. During quiet sleep, the electrocorticogram showed a slow wave-high voltage pattern; there were no eye movements and there was tonic activity on the nuchal electromyogram. During active sleep, the electrocorticogram showed a fast wave-low voltage pattern; there were rapid eye movements on the electrooculogram; there was no activity on the nuchal electromyogram; and there were occasional twitches of the ear, face, and limbs.

Experimental protocol. The lambs were studied in an environmental temperature of $25 \pm 1^{\circ} \mathrm{C}$. During an experiment, systemic and pulmonary arterial blood pressures, $\mathrm{Hb}$ oxygen saturations, pulmonary blood flow, and the electrophysiologic signals were recorded on a Grass model 7 polygraph (Grass Medical Instruments) and were digitized at $128 \mathrm{~Hz}$ (Zenith AT, Data Translation 2801A A/D, DATAQ WFS-200 Hardware Scroller, and Asystant+ Data Acquisition Software) for "off-line" analysis. Both environmental and lamb core temperatures were recorded using an Iso-Thermix Unit (Columbus Instruments, Dayton, $\mathrm{OH})$. The following calculations were made from the measured variables: arterial oxygen content $\left(\mathrm{CaO}_{2}\right)[\mathrm{Hb}$ concentration $(\mathrm{g} /$ $\mathrm{dL}) \times \mathrm{Hb} \mathrm{O}_{2}$ binding capacity $\left(1.36 \mathrm{~mL} \mathrm{O}_{2} / \mathrm{g} \mathrm{Hb}\right) \times \mathrm{SaO}_{2}$, where $\mathrm{SaO}_{2}$ is arterial blood oxygen saturation], mixed-venous oxygen content $\left(\mathrm{CvO}_{2}\right)[\mathrm{Hb}$ concentration $(\mathrm{g} / \mathrm{dL}) \times \mathrm{Hb} \mathrm{O}$ binding capacity $(1.36 \mathrm{~mL} \mathrm{O} / \mathrm{g} \mathrm{Hb}) \times \mathrm{SvO}_{2}$, where $\mathrm{SvO}_{2}$ is venous blood oxygen saturation, systemic oxygen transport (SOT) $\left(\mathrm{Qp} \times \mathrm{CaO}_{2}\right.$, where Qp is pulmonary blood flow), total body oxygen consumption $\left.\left(\mathrm{VO}_{2}\right) \mathrm{Qp} \times\left(\mathrm{CaO}_{2}-\mathrm{CvO}_{2}\right)\right]$, and total body oxygen extraction $\left[\left(\mathrm{VO}_{2} / \mathrm{SOT}\right) \times 100\right]$. $\mathrm{Hb}$ concentration was measured using an IL 282 Co-oximeter after calibration of the instrument with whole blood. The $\mathrm{Hb}$ of the whole blood used for instrument calibration was determined using the cyanmethemoglobin technique.

Measurements were made during a 1-min control period and during 1-min experimental periods at 10-min intervals for 120 min after i.v. administration of $0.3 \mu \mathrm{g}$ of bacterial pyrogen in seven carotid-intact lambs and six carotid-denervated lambs. Control measurements were made when the lambs were in quiet sleep. The bacterial pyrogen used was a lipopolysaccharide extracted from SAE (Difco Laboratories, Detroit, MI). In lambs, $0.3 \mu \mathrm{g}$ of SAE has been shown to produce a monophasic fever of about $0.7^{\circ} \mathrm{C}$ during this age range (8). Experiments began between 0800 and $1000 \mathrm{~h}$ each day to obviate possible superimposed effects of circadian rhythms.

Statistical analysis. For every animal, we determined an average value for each variable during each data collection period; these values were used for statistical analysis. We performed a two-factor analysis of variance for repeated measures of the same variable followed by a Duncan's multiple comparison test to determine if administration of bacterial pyrogen (control versus $10 \mathrm{~min}, 20 \mathrm{~min}, 30 \mathrm{~min}$, etc.) or carotid denervation (carotidintact versus carotid denervation) affected cardiac index, heart rate, stroke volume, systemic arterial blood pressure, systemic vascular resistance, pulmonary arterial blood pressure, arterial oxygen content, mixed-venous oxygen content, systemic oxygen transport, total body oxygen consumption, total body oxygen extraction, or body core temperature (12).

\section{RESULTS}

Intravenous administration of $0.3 \mu \mathrm{g}$ of SAE produced a shortlived monophasic fever of about $1^{\circ} \mathrm{C}$ in the carotid-intact lambs (Fig. 1). In contrast, a febrile response was not observed after i.v. administration of SAE in the carotid-denervated lambs.

In carotid-intact lambs, the rise in body core temperature began approximately $40 \mathrm{~min}$ after administration of SAE and continued for approximately $50 \mathrm{~min}$. This rise in body core temperature was preceded by the onset of shivering and an increase in total body oxygen consumption. The increase in total body oxygen consumption was met by an increase in total body oxygen extraction as systemic oxygen transport did not change (Table 1). Heart rate increased and stroke volume decreased between 40 and 70 min after administration of SAE; however 


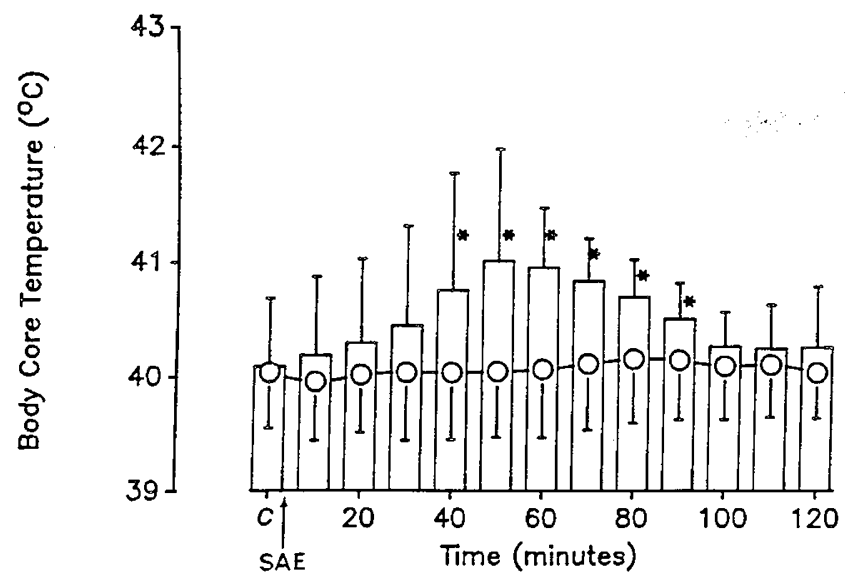

Fig. 1. Influence of bacterial endotoxin on body core temperature in carotid-intact ( $n=7$; open bars) and carotid-denervated $(n=6$; open circles) lambs. Data are means \pm 1 SD. *, Significant difference from control value within a group.

cardiac output did not change significantly (Table 2). Pulmonary arterial blood pressure increased after administration of SAE.

Carotid denervation produced changes in some of the cardiovascular variables during the control period (i.e. arterial oxygen content, cardiac index, heart rate, and pulmonary blood pressure). However, there were no additional significant changes in any of the metabolic or cardiovascular variables after administration of SAE.

Hypercapneic hypoxemia was observed in carotid-denervated lambs compared to carotid-intact lambs (Table 3). Because hypoxemia was observed in the carotid-denervated lambs and hypoxemia has been shown to diminish the thermogenic response to pyrogen in carotid-intact rats (13), guinea pigs (14), and lambs (15), experiments were repeated on three of the lambs when they were breathing an oxygen-enriched gas mixture that increased their arterial oxygen pressure to approximately 300 torr. A febrile response was still not observed after the administration of SAE in these lambs.

\section{DISCUSSION}

Our experiments provided new information about factors that influence the febrile response to a small dose of bacterial pyrogen in young lambs. Carotid denervation eliminated the febrile, metabolic, and cardiovascular responses as compared with those observed in carotid-intact lambs. Thus, intact carotid baroreceptors and/or chemoreceptors are important for the thermoregulatory response to a small dose of bacterial pyrogen in young lambs.

Intravenous administration of $0.3 \mu \mathrm{g}$ of $\mathrm{SAE}$ produced a shortlived fever of approximately $1^{\circ} \mathrm{C}$ in the carotid-intact lambs (Fig. 1). The increase in body core temperature was preceded by shivering - and most likely nonshivering - thermogenesis (1618 ) and a resulting increase in total body oxygen consumption. Neither an increase in body core temperature, total body oxygen consumption, nor shivering were observed after the administration of bacterial pyrogen in the carotid-denervated lambs.

It is important to point out that our carotid-denervation procedure not only eliminated afferents from the carotid baroreceptors but also eliminated afferents from the carotid chemo-

Table 1. Effect of i.v. administration of $0.3 \mu \mathrm{g}$ of SAE on systemic oxygen transport and systemic oxygen utilization in carotid-intact (CI) and carotid-denervated (CD) young lambs*

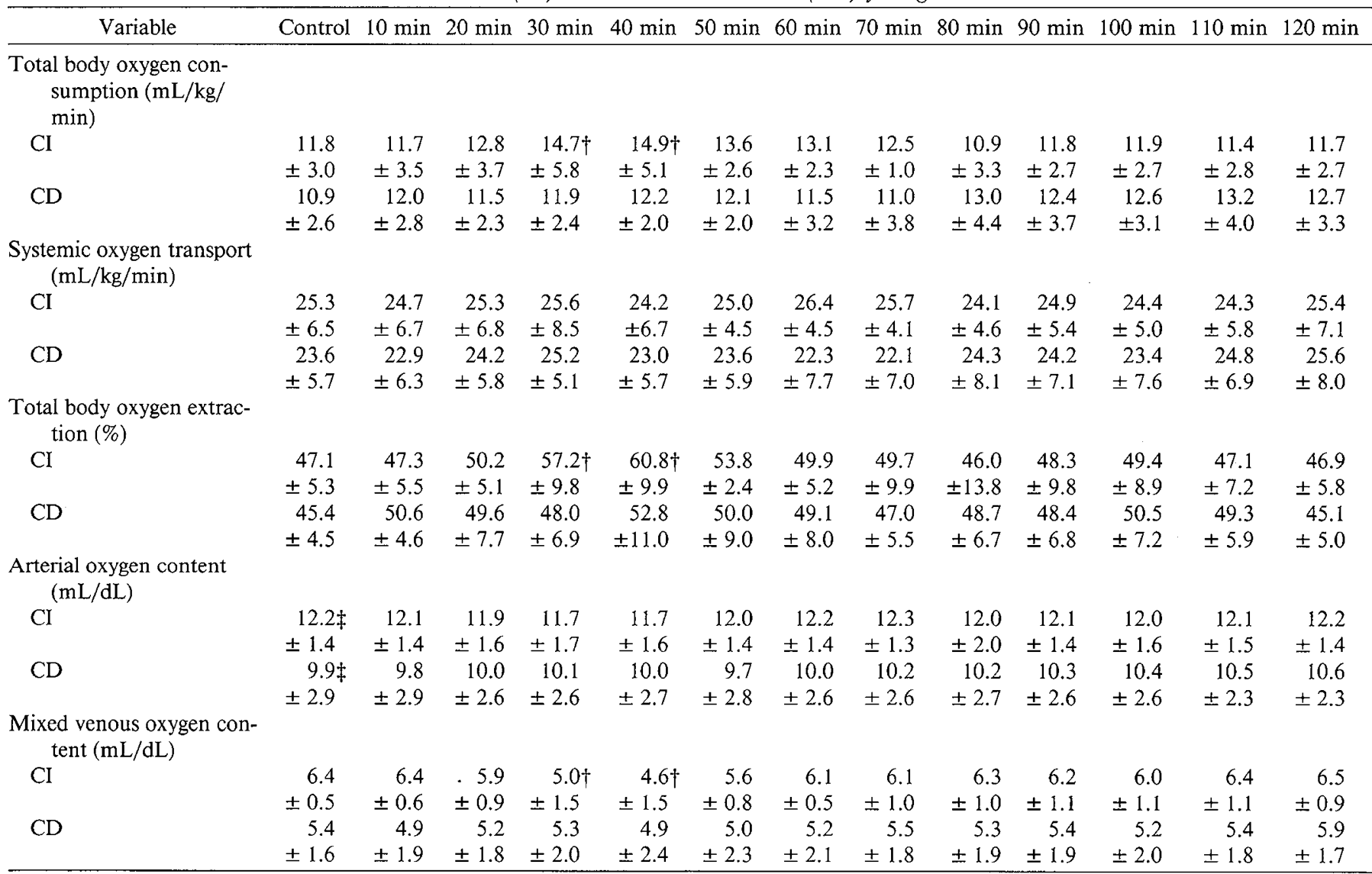

\footnotetext{
$*$ Values are means $\pm 1 \mathrm{SD}$.

$\dagger p<0.05$ for control vs time within a group.

$\ddagger p<0.05$ for $\mathrm{CI}$ control vs CD control.
} 
Table 2. Effect of i.v. administration of $0.3 \mu \mathrm{g}$ of SAE on cardiovascular variables in carotid-intact (CI) and carotid-denervated (CD) young lambs*

\begin{tabular}{|c|c|c|c|c|c|c|c|c|c|c|c|c|c|}
\hline Variable & Control & $10 \mathrm{~min}$ & $20 \min$ & $30 \mathrm{~min}$ & $40 \mathrm{~min}$ & $50 \min$ & $60 \mathrm{~min}$ & $70 \mathrm{~min}$ & 80 min & $90 \mathrm{~min}$ & $100 \mathrm{~min}$ & $110 \mathrm{~min}$ & $120 \mathrm{~min}$ \\
\hline \multicolumn{14}{|c|}{$\begin{array}{l}\text { Cardiac index }(\mathrm{mL} / \mathrm{kg} / \\
\min )\end{array}$} \\
\hline \multirow[t]{2}{*}{$\mathrm{CI}$} & $212 \ddagger$ & 207 & 217 & 224 & 212 & 213 & 220 & 213 & 206 & 207 & 206 & 205 & 211 \\
\hline & \pm 69 & \pm 67 & \pm 69 & \pm 79 & \pm 79 & \pm 54 & \pm 51 & \pm 49 & \pm 50 & \pm 47 & \pm 48 & \pm 61 & \pm 66 \\
\hline \multirow[t]{2}{*}{$\mathrm{CD}$} & $254 \ddagger$ & 254 & 257 & 264 & 245 & 266 & 239 & 235 & 258 & 250 & 246 & 254 & 261 \\
\hline & \pm 61 & \pm 60 & \pm 63 & \pm 69 & \pm 52 & \pm 68 & \pm 65 & \pm 58 & \pm 68 & \pm 56 & \pm 62 & \pm 60 & \pm 61 \\
\hline \multicolumn{14}{|l|}{ Heart rate (bpm) } \\
\hline \multirow[t]{2}{*}{$\mathrm{CI}$} & 166 & 164 & 182 & 185 & $189 \dagger$ & $195 \dagger$ & $201 \dagger$ & $192 \dagger$ & 171 & 168 & 169 & 166 & 164 \\
\hline & \pm 49 & \pm 37 & \pm 41 & \pm 44 & \pm 52 & \pm 38 & \pm 39 & \pm 39 & \pm 33 & \pm 37 & \pm 40 & \pm 36 & \pm 36 \\
\hline \multirow[t]{2}{*}{$\mathrm{CD}$} & 191 & 189 & 194 & 190 & 187 & 190 & 177 & 179 & 181 & 186 & 188 & 184 & 189 \\
\hline & \pm 42 & \pm 37 & \pm 37 & \pm 40 & \pm 34 & \pm 38 & \pm 39 & \pm 40 & \pm 43 & \pm 42 & \pm 47 & \pm 41 & \pm 40 \\
\hline \multicolumn{14}{|c|}{ Stroke volume $(\mathrm{mL} / \mathrm{kg})$} \\
\hline \multirow[t]{2}{*}{$\mathrm{CI}$} & 1.33 & 1.26 & 1.23 & 1.21 & $1.14 \dagger$ & $1.13 \dagger$ & $1.11 \dagger$ & $1.11 \dagger$ & 1.23 & 1.27 & 1.26 & 1.29 & 1.31 \\
\hline & \pm 0.40 & \pm 0.36 & \pm 0.31 & \pm 0.30 & \pm 0.29 & \pm 0.30 & \pm 0.34 & \pm 0.25 & \pm 0.35 & \pm 0.35 & \pm 0.36 & \pm 0.41 & \pm 0.38 \\
\hline \multirow[t]{2}{*}{$\mathrm{CD}$} & 1.33 & 1.35 & 1.32 & 1.35 & 1.35 & 1.42 & 1.35 & 1.35 & 1.45 & 1.33 & 1.33 & 1.38 & 1.40 \\
\hline & \pm 0.29 & \pm 0.23 & \pm 0.23 & \pm 0.24 & \pm 0.23 & \pm 0.21 & \pm 0.24 & \pm 0.26 & \pm 0.15 & \pm 0.14 & \pm 0.18 & \pm 0.17 & \pm 0.11 \\
\hline \multicolumn{14}{|c|}{$\begin{array}{l}\text { Systemic arterial pressure } \\
(\mathrm{mm} \mathrm{Hg})\end{array}$} \\
\hline \multirow[t]{2}{*}{$\mathrm{CI}$} & 72 & 75 & 79 & 77 & 73 & 71 & 72 & 70 & 75 & 81 & 81 & 80 & 80 \\
\hline & \pm 5 & \pm 10 & \pm 7 & \pm 10 & \pm 9 & \pm 10 & \pm 11 & \pm 8 & \pm 6 & \pm 8 & \pm 11 & \pm 11 & \pm 11 \\
\hline \multirow[t]{2}{*}{$\mathrm{CD}$} & 78 & 80 & 78 & 81 & 79 & 81 & 80 & 81 & 80 & 80 & 79 & 81 & 81 \\
\hline & \pm 7 & \pm 6 & \pm 8 & \pm 6 & \pm 6 & \pm 5 & \pm 7 & \pm 9 & \pm 10 & \pm 10 & \pm 10 & \pm 11 & \pm 8 \\
\hline \multicolumn{14}{|c|}{$\begin{array}{l}\text { Systemic vascular resist- } \\
\text { ance }(\mathrm{mm} \mathrm{Hg} / \mathrm{mL} / \\
\mathrm{kg} / \mathrm{min})\end{array}$} \\
\hline \multirow[t]{2}{*}{$\mathrm{CI}$} & 0.383 & 0.411 & 0.417 & 0.404 & 0.403 & 0.374 & 0.371 & 0.366 & 0.389 & 0.414 & 0.407 & 0.426 & 0.413 \\
\hline & \pm 0.125 & \pm 0.154 & \pm 0.139 & \pm 0.148 & \pm 0.137 & \pm 0.124 & \pm 0.122 & \pm 0.119 & \pm 0.111 & \pm 0.115 & \pm 0.089 & \pm 0.117 & \pm 0.138 \\
\hline \multirow[t]{2}{*}{$\mathrm{CD}$} & 0.322 & 0.332 & 0.323 & 0.325 & 0.333 & 0.333 & 0.358 & 0.362 & 0.338 & 0.350 & 0.350 & 0.348 & 0.340 \\
\hline & \pm 0.079 & \pm 0.086 & \pm 0.099 & \pm 0.085 & \pm 0.078 & \pm 0.071 & \pm 0.069 & \pm 0.095 & \pm 0.111 & \pm 0.083 & \pm 0.082 & \pm 0.093 & \pm 0.091 \\
\hline \multicolumn{14}{|c|}{$\begin{array}{l}\text { Pulmonic arterial blood } \\
\text { pressure }(\mathrm{mm} \mathrm{Hg})\end{array}$} \\
\hline \multirow[t]{2}{*}{$\mathrm{CI}$} & $18 \ddagger$ & 18 & $27 \dagger$ & $32 \uparrow$ & $30 \dagger$ & $26 \dagger$ & $25 \dagger$ & 22 & 19 & $25 \dagger$ & $26 \dagger$ & $27 \dagger$ & 22 \\
\hline & \pm 4 & \pm 6 & \pm 15 & \pm 16 & \pm 19 & \pm 13 & \pm 12 & \pm 11 & \pm 8 & \pm 11 & \pm 8 & \pm 13 & \pm 11 \\
\hline \multirow[t]{2}{*}{$\mathrm{CD}$} & $26 \ddagger$ & 30 & 27 & 31 & 29 & 30 & 31 & 30 & 30 & 29 & 29 & 29 & 27 \\
\hline & \pm 10 & \pm 13 & \pm 15 & \pm 15 & \pm 6 & \pm 8 & \pm 9 & \pm 12 & \pm 12 & \pm 9 & \pm 14 & \pm 13 & \pm 14 \\
\hline
\end{tabular}

$*$ Values are means $\pm 1 \mathrm{SD}$.

$\dagger p<0.05$ for control $v s$ time within a group.

$\ddagger p<0.05$ for $\mathrm{Cl}$ control vs $\mathrm{CD}$ control.

Table 3. Influence of bacterial pyrogen and fraction of inspired oxygen on arterial blood gases and pH in carotid-intact and carotid-denervated lambs*

\begin{tabular}{|c|c|c|c|c|c|}
\hline & Control & $30 \mathrm{~min}$ & $60 \mathrm{~min}$ & $90 \mathrm{~min}$ & $120 \mathrm{~min}$ \\
\hline \multicolumn{6}{|c|}{ Carotid-intact $\left(\mathrm{FIO}_{2} 0.21 ; n=7\right)$} \\
\hline $\mathrm{pHa}$ & $7.41 \pm 0.03$ & $7.39 \pm 0.04$ & $7.41 \pm 0.03$ & $7.41 \pm 0.04$ & $7.40 \pm 0.03$ \\
\hline $\mathrm{PaO}_{2}$ & $73 \pm 6$ & $62 \pm 12$ & $72 \pm 9$ & $74 \pm 10$ & $72 \pm 11$ \\
\hline $\mathrm{PaCO}_{2}$ & $37 \pm 3$ & $37 \pm 6$ & $37 \pm 4$ & $35 \pm 4$ & $38 \pm 5$ \\
\hline \multicolumn{6}{|c|}{ Carotid-denervated $\left(\mathrm{FIO}_{2} 0.21 ; n=6\right)$} \\
\hline $\mathrm{pHa}$ & $7.36 \pm 0.02$ & $7.37 \pm 0.02$ & $7.36 \pm 0.01$ & $7.37 \pm 0.02$ & $7.38 \pm 0.02$ \\
\hline $\mathrm{PaO}_{2}$ & $57 \pm 13$ & $49 \pm 7$ & $55 \pm 4$ & $58 \pm 8$ & $50 \pm 15$ \\
\hline $\mathrm{PaCO}_{2}$ & $50 \pm 3$ & $54 \pm 6$ & $48 \pm 9$ & $51 \pm 3$ & $52 \pm 9$ \\
\hline \multicolumn{6}{|c|}{ Carotid-denervated $\left(\mathrm{FIO}_{2} 0.60 ; n=3\right)$} \\
\hline $\mathrm{pHa}$ & $7.36 \pm 0.04$ & $7.39 \pm 0.07$ & $7.41 \pm 0.05$ & $7.41 \pm 0.04$ & $7.40 \pm 0.07$ \\
\hline $\mathrm{PaO}_{2}$ & $293 \pm 16$ & $311 \pm 11$ & $311 \pm 27$ & $313 \pm 22$ & $334 \pm 20$ \\
\hline $\mathrm{PaCO}_{2}$ & $41 \pm 0$ & $41 \pm 2$ & $41 \pm 7$ & $37 \pm 1$ & $41 \pm 1$ \\
\hline
\end{tabular}

* Data are means $\pm 1 \mathrm{SD}$. $\mathrm{FIO}_{2}$, fraction of inspired oxygen; pHa, arterial pH; $\mathrm{PaO}_{2}$, arterial $\mathrm{O}_{2}$ tension; and $\mathrm{PaCO}_{2}$ arterial $\mathrm{CO}_{2}$ tension.

receptors. The effectiveness of our carotid-denervation procedure is proved by the following evidence. First, hypoventilation and hypoxemia were observed during resting conditions (Table 3 ) as compared with carotid-intact animals. Second, this procedure eliminated the early respiratory frequency response to rapidly developing hypoxemia as compared with intact animals (19).

As far as we are aware, there are no other reports in the literature regarding the influence of carotid baroreceptors and/ or chemoreceptors on the febrile response to bacterial pyrogen.
However, Gautier et al. (20) have shown that carotid denervation does not alter the shivering thermogenic response to cold in adult unanesthetized cats. Similarly, Blatteis (4) showed that carotid sinus nerve section does not prevent either the metabolic response to cold of neonatal rabbits or its depression by hypoxia. Furthermore, Wilson and Fyda (9) have shown that discrete bilateral lesions of the NTS influence the coregulation of nutritive and heat conserving/dissipating functions of the circulation in response to changes in the ambient temperature in rats. Although 
NTS lesion has a negligible effect on the animals' ability to regulate rectal temperature over the short term, the effector mechanisms used to thermoregulate are altered. In response to a mild cold challenge $\left(e . g .19,15\right.$, or $\left.11^{\circ} \mathrm{C}\right)$, which should activate similar effector mechanisms as bacterial pyrogen, the NTS-lesioned animals show an accentuated pressor response but an attenuated metabolic response compared to sham-operated animals.

Although this study was not designed to determine the mechanism of the altered febrile response in carotid-denervated lambs, our findings allow us to rule out certain possibilities and to speculate upon the mechanism. There are at least four possibilities: the first is that arterial hypoxemia after carotid denervation diminishes the thermogenic response to bacterial pyrogen as we have previously observed in carotid-intact lambs (15); the second is that carotid denervation alters the formation of endogenous pyrogen (e.g. IL-1, tumor necrosis factor) after injection of exogenous pyrogen; the third is that carotid denervation alters the CNS response to endogenous pyrogen; and the fourth is that carotid-denervation alters the coregulation of nutritive and heat conserving/dissipating functions of the circulation such that effector mechanisms are not capable of increasing body temperature.

We believe that it is unlikely that the degree of hypoxemia observed in our animals after carotid denervation attenuated the thermogenic response to bacterial pyrogen because a fever was still not observed when three of the lambs were retested while breathing an oxygen-enriched gas mixture. Furthermore, we are unaware of any data that suggest that carotid denervation alters the formation of endogenous pyrogen after injection of exogenous pyrogen and think that it is highly unlikely to be responsible for our results. Lastly, we did not observe a change in systemic arterial blood pressure or systemic vascular resistance after injection of bacterial pyrogen in either group and thus do not think that an ineffective shift in effector mechanisms (e.g. decreased metabolic response and increased heat conserving response) is responsible for the lack of a response.

It is possible that carotid denervation alters the CNS response to endogenous pyrogen. Numerous investigations have provided evidence that both the carotid $(21,22)$ and aortic (23) baroreceptors reflexly affect plasma concentrations of arginine vasopressin. Furthermore, recent evidence has been provided that chronic sinoaortic denervation produces time-related, region-specific changes in brain arginine vasopressin in adult rats (24). This information, taken with the evidence that arginine vasopressin may function as an antipyretic substance in the brain (6), allows one to formulate the hypothesis that the lack of a febrile response may be due to a regional specific increase in brain arginine vasopressin concentration after chronic carotid denervation. However, this hypothesis remains to be tested. Kasting et al. (25) have provided evidence that mild hemorrhage, which results in an increased concentration of arginine vasopressin in plasma, attenuates the febrile response to bacterial endotoxin in sheep.

Pulmonary arterial blood pressure increased significantly after the administration of bacterial pyrogen in the carotid-intact lambs but not in the carotid-denervated lambs. An increase in pulmonary arterial pressure and pulmonary vascular resistance has been observed by a number of investigators after experimental sepsis (26) or after the administration of endotoxin $(27,28)$. Although the mechanism of the pulmonary vasoconstriction is not perfectly clear, recent data provide evidence that thromboxane $\mathrm{A}_{2}$ plays a major role $(29,30)$. The most likely reason for the lack of a pulmonary vascular response after administration of bacterial pyrogen in the carotid-denervated lambs is that their pulmonary vascular bed was preconstricted by the arterial hypoxemia that followed carotid denervation.

In summary, we have shown that carotid denervation eliminates the febrile, metabolic, and cardiovascular responses to a small dose of bacterial pyrogen in young lambs. The mechanism for the altered response remains to be determined.

\section{REFERENCES}

1. Blatteis CM 1975 Postnatal development of pyrogenic sensitivity in guinea pigs. J Appl Physiol 39:251-257

2. Smith RT, Thomas L 1954 Influence of age upon response to meningococcal endotoxin in rabbits. Proc Soc Exp Biol Med 86:806-809

3. Pittman QJ, Cooper KE, Veale WL, van Petten FR 1973 Fever in newborn lambs. Can J Physiol Pharmacol 51:868-872

4. Blatteis CM 1964 Hypoxia and the metabolic response to cold of newborn rabbits. J Physiol (Lond) 172:358-368

5. Alexander G 1961 Temperature regulation in the newborn lamb. III. Effect of environmental temperature on metabolic rate, body temperatures, and respiratory quotient. Aust J Agric Res 12:1152-1174

6. Cooper KE, Kasting NW, Lederis K, Veale WL 1979 Evidence supporting a role for endogenous vasopressin in natural suppression of fever in the sheep. J Physiol (Lond) 295:33-45

7. Kasting NW, Wilkinson MF 1987 Vasopressin functions as an endogenous antipyretic in the newborn. Biol Neonate 51:249-254

8. Fewell J, Ricciuti F, Kondo C, Dascalu V 1991 Fever in young lambs: temperature, cardiovascular and metabolic responses to a small dose of bacterial pyrogen. J Dev Physiol 15:229-235

9. Wilson JR, Fyda DM 1985 Nucleus tractus solitarii (NTS): does it mask the interaction of blood pressure and thermal energetics? In: Beamish RE, Singal PK, Ohalla NS (eds) Stress and Heart Disease. Martinus Nijhoff, Boston, pp 99-115

10. Appleton $A B$, Waites GMH 1957 A surgical approach to the superior cervical ganglion and related structures in the sheep. J Physiol (Lond) 135:52-57

11. Bureau MA, Lamarche J, Foulon P, Dalle D 1985 Postnatal maturation of respiration in intact and carotid body-chemodenervated lambs. J Appl Physiol 59:869-874

12. Winer BJ 1971 Single-factor experiments having repeated measures on the same elements. In: Statistical Principles in Experimental Design. McGrawHill, New York, pp 261-308

13. Farkas M, Mozda SZ, Donhoffer SZ 1966 The effect of hypoxic hypoxia and environmental temperature on body temperature and oxygen consumption in the course of pyrogen-induced fever. Acta Physiol Acad Sci Hung 30:155160

14. Doherty Jr DW, Blatteis CM 1980 Hypoxic reduction of endotoxic fever in guinea pigs. J Appl Physiol 49:294-299

15. Ricciuti F, Fewell J, Kondo C, Dascalu V 1990 Fever in young lambs: hypoxemia alters the febrile response to a small dose of bacterial pyrogen. Proceedings of the 17 th International Meeting of the Society for the Study of Fetal Physiology, Pacific Grove, CA (abstr)

16. Blatteis CM 1976 Effect of propranolol on endotoxin-induced pyrogenesis in newborn and adult guinea pigs. J Appl Physiol 40:35-39

17. Harris WH, Foster DO, Nadeau BE 1985 Evidence for a contribution by brown adipose tissue to the development of fever in the young rabbit. Can J Physiol Pharmacol 63:595-598

18. Szekely M, Szelenyi Z, Sumegi I 1973 Brown adipose tissue as a source of heat during pyrogen-induced fever. Acta Physiol Acad Sci Hung 43:85-88

19. Fewell JE, Kondo CS, Dascalu V, Filyk SC 1989 Influence of carotid denervation on the arousal and cardiopulmonary response to rapidly developing hypoxemia in lambs. Pediatr Res 25:473-477

20. Gautier H, Bonora M, Schultz SA, Remmers JE 1987 Hypoxia-induced changes in shivering and body temperature. J Appl Physiol 62:2477-2484

21. Chien S, Peric B, Usami S 1962 The reflex nature of release of antidiuretic hormone upon common carotid occlusion in vagotomized dogs. Proc Soc Exp Biol Med 111:193-196

22. Share L, Levy MN 1966 Carotid sinus pulse pressure, a determinant of plasma antidiuretic hormone concentration. Am J Physiol 211:721-724

23. Bond GC, Trank JW 1972 Plasma antidiuretic hormone concentration after bilateral aortic nerve section. Am J Physiol 222:595-598

24. Alexander N, Morris M 1988 Effects of chronic sinoaortic denervation on central vasopressin and catecholamine systems. Am J Physiol 255:R768R773

25. Kasting NW, Veale WL, Cooper KE, Lederis K 1981 Effect of hemorrhage on fever: the putative role of vasopressin. Can J Physiol Pharmacol 59:324-328

26. Rojas B, Green RS, Hellerqvist CG, Olegard R, Brigham KL, Stahlman MT 1981 Studies on group B-hemolytic streptococcus. II. Effects on pulmonary hemodynamics and vascular permeability in unanesthetized sheep. Pediatr Res 15:899-904

27. Harlan J, Winn R, Harker L, Hildebrandt J 1983 Thromboxane $A_{2}$ inhibits lung vasoconstriction but not permeability after endotoxin. $\mathrm{J}$ Clin Invest 72:911-918

28. Watkins WD, Huttermeier PC, Kong D, Peterson MB 1982 Thromboxane and pulmonary hypertension following $E$. coli endotoxin infusion in sheep: effect of an imidazole derivative. Prostaglandins 23:273-285

29. Truog WE, Sorensen GK, Standaert TA, Redding GJ 1986 Effects of the thromboxane synthetase inhibitor, dazmegrel (UK 38,485 ), on pulmonary gas exchange and hemodynamics in neonatal sepsis. Pediatr Res 20:481-486

30. Truog WE, Gibson RL, Juul SE, Henderson WR, Redding GJ 1988 Neonatal group B streptococcal sepsis: effects of late treatment with dazmegrel. Pediatr Res 23:352-356 